\title{
Comitês de Ética em Pesquisa: da linguagem técnico-cientifica à normatização
}

Committees of ethics in research: from technical and scientific language to normatization

Comités de ética en la investigación: desde el lenguaje técnico y científico hasta la normalización

Tanise Zago Thomasi ${ }^{11}$

RESUMO: o objetivo desse artigo é discutir a atuação dos Comitês de Ética em Pesquisa e sua responsabilidade pela adoção de futuras políticas públicas sanitárias. Primeiro, apresentamos as particularidades institucionais, funcionais e organizacionais do Sistema CEP/CONEP instituídas pela Resolução n. 196/1996 do CNS e posteriormente as alterações sofridas em decorrência da aprovação da Resoluções n. 466/2012 e 510/2016 também do CNS e suas influências nacionais. Para tanto, investigamos suas diretrizes legais, aliadas ao Sistema Único de Saúde (SUS), avaliando o emprego da linguagem técnico-científica. Finalmente, polemizamos a importância da emissão de pareceres técnicos sobre a pesquisa envolvendo seres humanos, como os responsáveis pela afirmação do direito sanitário brasileiro, analisando o polêmico processo judicial envolvendo a população ribeirinha do estado do Amapá, que passou a ser conhecido como "cobaias humanas". Concluímos, na sequência, que os Comitês de Ética em Pesquisa é a organização responsável pelo futuro do sistema saúde, justamente, pelas comunicações institucionais estabelecidas quando da autorização da realização dos estudos envolvendo seres humanos.

Palavras-chave: Comitês de Ética em Pesquisa. Seres Humanos. Pesquisa. Resoluções.

ABSTRACT: The aim of this article is to discuss the role of the Ethics in Research and its responsibility for the adoption of future health policies. First, we present the institutional, functional and organizational characteristics of the system CEP / CONEP established by Resolution no. 196/1996 CNS and subsequently the changes suffered as a result of the approval of Resolution no. 466/2012 and no. 510/2016 also from CNS and its national influences. To this end, we investigate its legal guidelines, combined with the Single Health System (SUS), evaluating the use of technical-scientific language. Finally, the importance of including expert opinions on research involving human subjects, as those responsible for the affirmation of brazilian health law, analyzing the controversial court case involving the local population of Amapá state, which has become known as "human guinea pigs". We concluded, following which the Research Ethics Committee is the organization responsible for the future of the health system, precisely by established institutional communications when the authorization of such studies involving human subjects.

Keywords: Research Ethics Comitees. Humans Being. Research. Resolutions.

\footnotetext{
${ }^{1}$ Professora universitária na Universidade Tiradentes e Centro Universitário AGES; Graduada em Direito pela Universidade Católica de Pelotas; Mestre em Direito pela Universidade de Caxias do Sul. Email para contato: tanisethomasi@gmail.com
} 
RESUMEN: El objetivo de este artículo es analizar el desempeño de los comités de ética de la investigación y su responsabilidad en la adopción de las futuras políticas públicas. Presentamos el relator institucional, funcional y organizacional del sistema CEP/CONEP impuesta por la Resolución n 196/1996 de el Consejo Nacional de Salud y los cambios debidos a la aprobación de las resoluciones $n^{\circ}$. 466/2012 y 510/2016 del CNS y sus influencias nacionales. Para ello, investigamos las directrices legales, con el Sistema Unificado de Salud (SUS), evaluando el uso de la ciencia de la lengua. Por fin, hay discusión sobre la importancia del asesoramiento técnico sobre la investigación en seres humanos, tales como los responsables de la afirmación del derecho a la salud en Brasil, analizando el corte polémico caso que involucra a la población pobre del estado de Amapá, que llegó a ser conocido como "conejillos de indias" humanos. Concluimos que los comités de ética en la investigación es la organización responsable para el futuro del sistema de salud, necesitamos de comunicaciones institucionales establecidas cuando la autorización de la culminación de los estudios con seres humanos.

Palabras-Ilave: Comités de Ética de la Investigación. Los Seres Humanos. Investigación. Resoluciones.

\section{Introdução}

As questões relativas à biomedicina tendem cada vez mais a compor a realidade das sociedades contemporâneas. Assuntos como clonagem, terapias gênicas e desenvolvimento de novos medicamentos, por exemplo, passam a fazer parte dos diálogos corriqueiros de pessoas comuns, ou seja, daquelas que não estão inseridas no contexto das pesquisas. Estudos científicos recentemente noticiados salientaram a iminência de ser realizado o primeiro transplante de cabeça do mundo, no qual, esta será transposta para um novo corpo humano, com todas as funções fisiológicas preservadas.

Diante da abrangência de tal anúncio despertou-se o chamado 'senso comum', a preocupação acerca da coerência ética de protocolos médico-científicos nesse tipo de procedimento. Esta preocupação se fundamenta mediante a relevância do conhecimento dos direitos assim como do respeito à própria cidadania conquistada pelos indivíduos.

Eventos científicos deste porte ficaram internacionalmente conhecidos como 'abusos de pesquisadores', a citar a experiência realizada em Macon, Alabama, no ano de 1932, em que pacientes portadores de sífilis não receberam propositadamente nenhum tipo de tratamento, para que os pesquisadores pudessem acompanhar a evolução da doença. Tal fato só foi descoberto 40 anos depois, em 1972. Na sequência, a Guatemala, entre $1946 \mathrm{e}$ 1948, infectou de maneira intencional, prisioneiros e doentes mentais com as bactérias da sífilis e gonorreia para, posteriormente, testar a eficácia de antibióticos. 
O Brasil contribui para esses exemplos com o famoso estudo envolvendo comunidades ribeirinhas do Estado do Amapá, no ano de 2003 a 2006, pois, pessoas foram pagas para "alimentarem" mosquitos com seu próprio sangue, no intuito de capturálos, e posteriormente, contribuírem no avanço do estudo da malária. Mediante este tipo de ocorrência, normatizações internacionais buscam fortalecer os mecanismos de proteção da sociedade, viando evitar abusos cometidos por cientistas eticamente descompromissados com o bem-estar físico e legal dos seres vivos, principalmente os humanos. Ao revés, fazse necessário pontuar a relevância do avanço tecnológico no que se refere à busca pela qualidade de vida e a evolução da humanidade, enquanto algo imperioso. No ano de 1988, o Brasil editou a Resolução $n .{ }^{\circ} 1$, contendo as tendências nacionais para a investigação médica. Ainda que de forma tímida, este documento trouxe à tona discussões sobre questões éticas como as referentes à vigilância sanitária e à biossegurança. No entanto, o fato de não ter havido adesões significativas contribuiu para a elaboração da Resolução do Conselho Nacional de Saúde n. o 196/96, com vertente exclusivamente bioética, priorizando o ser humano e toda a sua complexidade.

Ainda acerca da relevância do homem em sua integralidade, foram criados os Comitês de Ética em Pesquisa (CEP), com enfoque multi e interdisciplinar, distinguindo conflitos de valores, retratando dilemas e avaliando as questões éticas da pesquisa de forma a enaltecer a proteção da dignidade do ser humano. São eles os responsáveis pelo parecer final da realização ou não de um estudo clínico. A referida normatização foi atualizada em 13 de julho de 2012, originando a Resolução n. ${ }^{\circ} 466 / 2012$, que hoje trata da matéria de forma mais aperfeiçoada, considerando a experiência anterior e preconizando ainda mais o consentimento livre e esclarecido dos envolvidos. Posteriormente, em 7 de abril de 2016 foi editada a Resolução de n. 510 aperfeiçoando a temática, principalmente quanto às particularidades do assentimento/consentimento.

No entanto, apesar das supracitadas inserções jurídicas, permanece o impasse referente à participação dos membros das pesquisas, pois, praticamente todos integrantes são provenientes das áreas médicas, assim, a ausência de profissionais de outros campos do conhecimento dificulta a tomada de posição e a implementação de uma visão mais integral do homem, já que determinados ramos do saber não são incluídos, ficando aquém do processo. 
De forma ilustrativa, será apresentado o caso verídico sobre a decisão judicial envolvendo a pesquisa norte americana intitulada 'Homogeneidade de vetores de malária no Amapá', iniciada em 2003, cujo objetivo era analisar os vários tipos de transmissores da malária na região. A pesquisa teve a suspensão decretada pelo Conselho Nacional de Saúde, ao ser comprovado que os ribeirinhos estavam sendo convidados para permitir serem picados por mosquitos, durante a marcação e recaptura do vetor, em troca de pagamento.

Neste interim, a pesquisa envolvendo seres humanos necessita ser discutida nas dimensões institucional, organizacional e profissional-técnica, pois, somente a visão sistêmica será capaz de justificar a decisão discricionária pela realização ou não dos estudos e, consequentemente, contribuir para a existência de uma sociedade pautada nos preceitos da justiça, fraternidade e solidariedade, como preconiza a Carta Magna de 1988, no ápice do estado democrático de direito.

\section{Pesquisas Envolvendo Seres Vivos e seu Entorno}

Os estudos médicos e a prática da medicina estão cada vez mais complexas diante do surgimento de inúmeras especialidades com empenho na busca por tratamentos que levem à cura de grande maioria das doenças existentes. Neste contexto, os avanços biomédicos tendem a intervir de forma a alterar a cultura e os valores sociais, ao possibilitarem mecanismos que indicam proximidade de eventos como existência da sonhada 'fonte da juventude'.

Argumenta-se que protocolos médicos ousados e nem sempre confiáveis despertam a cobiça e estima de pessoas que deixam de ser 'pacientes para serem impacientes' não aceitando com naturalidade a realidade humana, inclusive buscando os profissionais de saúde como quem se dirige às prateleiras dos supermercados, para a compra de itens nem sempre essenciais (1), em um comportamento que chega a alterar as atuais condições de vida de todos.

Os tratamentos de saúde e as pesquisas neste setor representam a esperança para aqueles que estão acometidos por algum tipo de enfermidade, porém, como produto da sociedade, não se pode esquecer as influências que estes sofrem e oportunizam no mundo imbricado pela confiabilidade dos resultados obtidos nas pesquisas científicas e 
nos efeitos produzidos em cada usuário, já que a saúde é imprevisível. A tomada de decisão é que converterá a certeza em risco, como preconiza Luhmann (2)

Conforme o sentido 'popperiano' e sua teoria da falsibilidade (3), ao procurar investigar e responder aos questionamentos de forma mais sólida possível, é confiado à ciência o principio da incerteza, obrigando, por vezes, que os estudos retornem ao estágio inicial por falta de comprovação. Assim, tal fato comprova a existência de seguinte paradoxo: "apesar de um extraordinário aumento do conhecimento, estamos em um estado de maior incerteza e de menor satisfação e felicidade. Fala-se aos pacientes com números e não mais com o coração" (1), pois o que importa são as estatísticas indicadas pela pesquisa realizada.

No sentido de que tudo pode ser prevenido, cultua-se a chamada medicina defensiva, segundo a qual, os estudos clínicos são capazes de comprovar as mais diversas 'verdades', inclusive a negação da morte já que a pesquisa científica pode explicar todos os dilemas, não havendo limites para sua atuação. Nesta perspectiva, até mesmo pessoas sadias devem ser tratadas, pois, ações cotidianas passam a ter maior amplitude e assim, por exemplo, "como e quando comer não é mais apenas um prazer, mas um dever estabelecido pela lista de dieta pendurada na porta da geladeira"(1)

Estima-se que o medo generalizado é uma característica marcante da população mundial que passou a confiar fielmente em estatísticas e eleger a prevenção como o objetivo de sua existência, contribuindo para um aumento significativo das pesquisas envolvendo seres vivos, apesar de muitos não concordarem em participarem deste tipo de estudos, justamente pela insegurança que proporcionam.

Preocupado com essa tendência mundial, o Brasil editou regulamentações que

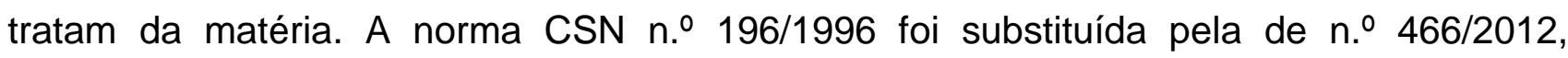
disciplinando as pesquisas e os testes em seres humanos, afirmando que elas devem priorizar a ética e o bem-estar dos envolvidos, de forma que estejam devidamente esclarecidos e informados acerca dos riscos e benefícios implicados nas ações. Ademais, trouxe termos e condições a serem seguidos dentro do Sistema Comitês de Ética em Pesquisa-CEP/Comissão Nacional de Ética em Pesquisa-CONEP, compondo um sistema que utiliza mecanismos, ferramentas e instrumentos próprios de interrelação na proteção dos direitos e dos deveres dos participantes. Fato confirmando pela novel Resolução de n.ำ 510 de 2016. 
Dessa feita, a supracitada alteração ressaltou o respeito pela dignidade humana, aliado ao desenvolvimento e ao engajamento ético inerente ao progresso científico e tecnológico, enquanto fundamentais para que se possa desvendar uma ampla percepção da vida com reflexos na cultura, no comportamento, nos meios reais e virtuais disponíveis, enquanto fatores que alteram e inovam em ritmo acelerado e contínuo.

Por estas razões, as pesquisas médico-científicas devem promover o bem-estar, a defesa e preservação do meio ambiente, para as presentes e futuras gerações, demonstrando que sua influência está diretamente relacionada com o porvir, ou seja, que a aprovação de um determinado estudo clínico pode impactar a realidade dos indivíduos, sendo objeto de estudo as influências que sua comunicação (4). Machado (4) entende que essas "comunicações são definidas sob viés psicológico, mas como processo de produção de sentido a partir de um emissor, de um transmissor e de um receptor de determinada mensagem". Também Bordieu (5) essa comunicação seria o verdadeiro conceito de habitus, nas suas estruturas estruturantes e estruturadas, distinguindo o conhecimento especializado e estabelecendo regras e lógicas próprias.

Diante dos expostos, ressalta-se a necessidade de discutir as pesquisas mediante o enfoque desse processo social de reconhecimento assim como das peculiaridades de sua atuação, ou seja, de que forma institucionaliza percepções e atitudes em relação ao trabalho e seu entorno organizacional (4). Para tanto, os códigos sociais utilizados, impactam a cultura, que por sua vez, legitimará ou não a prática (5), evitando a manifestação do poder judiciário sobre o dilema dos estudos envolvendo seres humanos.

No que diz respeito às instituições jurídicas, estas são conclamadas a exarar parecer técnico sobre as práticas científicas, no sentido de possibilitar a abertura do sistema 'para dentro de si', sempre que houver conflito na atuação da organização, pois, conforme a visão sistêmica compete ao Poder Judiciário decidir em última instância as incongruências sociais. Essa dinâmica é a burocracia weberiana, que pretende simplesmente reduzir complexidade, ou na vertente luhmaniana, o input e output, sendo ilustrado pela imagem da corrida de bastão (4), onde existe uma verdadeira cooperação, já que um depende do outro.

As prescrições legais referentes aos procedimentos científicos dificilmente possuem justificativa moral para a tomada de uma posição em função da ausência de um parâmetro anterior, seja ele de qualquer ordem, exigindo a abertura do sistema para ser 'processado 
internamente por ele' e devolvido ao cerne da discussão. Assim, o 'resultado' passa a ser considerado o referencial para o tipo de situação. Nesse sentido, pretende-se arguir que as decisões adotadas pelos Comitês de Ética em Pesquisa possam ser autorreferentes para a aceitação de determinados protocolos médicos que causem impactos à realidade dos cidadãos que conferem credibilidade aos estudos clínicos realizados, pois:

O principal instrumento de isolamento é o mito institucional, o que se refere a determinadas representações sociais relacionada à estrutura e às funções da organização, com elevado grau de impessoalidade, atuando como mecanismo que atribui natureza técnica às práticas, meios e fins da organização ${ }^{4}$

Faz-se necessário analisar as atribuições concernentes as Comissões de Ética em Pesquisa com o intuito de comprovar seu poder de normatização a partir do emprego da linguagem técnico-cientifica, defendendo a existência de uma carreira profissional que impacta as pesquisas envolvendo seres humanos e, consequentemente, o próprio modo de viver.

\section{Do Comitê de Ética em Pesquisa (CEP)}

Conforme o tópico VII da Resolução n.ำ466/2012, o sistema CEP/CONEP é composto pela Comissão Nacional de Ética em Pesquisa - CONEP/CNS/MS do Conselho Nacional de Saúde e pelos Comitês de Ética em Pesquisa (CEP), estabelecendo um sistema que utiliza mecanismos, ferramentas e instrumentos próprios de interrelação em um trabalho cooperativo que visa, especialmente, a proteção dos participantes em pesquisa do Brasil, atuando de forma coordenada e descentralizada por meio de um processo de acreditação. É expresso ao esclarecer tratar-se de uma instância colegiada de natureza consultiva, deliberativa, normativa, educativa e independente, vinculada ao Conselho Nacional de Saúde/MS (VII.3 da Resolução n. 466/2012).

É responsabilidade do referido órgão a decisão sobre a realização de pesquisas envolvendo seres humanos e, para tanto, os Comitês de Ética em Pesquisa são colegiados interdisciplinares e independentes de ampla relevância pública, com caráter consultivo, deliberativo e educativo, criados com o objetivo de defender os interesses dos participantes em pesquisa, sua integridade e dignidade contribuindo para 0 desenvolvimento da pesquisa dentro dos padrões éticos. Nesse sentido, a Resolução 
n.510 de 2016 preocupou-se em disciplinar os pormenores do consentimento/assentimento dos envolvidos nos estudos.

O Comitê de Ética em Pesquisa preocupa-se também com a atuação dos seus membros concedendo-Ihes total autonomia na tomada das decisões, sendo que estas devem ser confidenciais e, para tanto, entende que a atuação dos envolvidos não pode ser remunerada, admitindo apenas a possibilidade de serem reembolsados em caso de eventuais despesas efetuadas, além de lhes garantir a dispensa dos seus respectivos trabalhos, tendo em vista a relevância pública da função que desempenham. Faz-se necessário conhecer as atribuições, competências e procedimentos de análise ética dos membros integrantes do colegiado, enquanto sujeitos que devem pautar seus atos e decisões em função da garantia do respeito à dignidade dos participantes dos estudos científicos.

\section{Atuação}

O Comitê de Ética em Pesquisa (CEP) é um sistema interdisciplinar e independente, constituindo um munus público. Conforme os preceitos legais, toda instituição que realiza pesquisa envolvendo seres humanos deve possuí-lo, pois, é sua responsabilidade a defesa dos interesses de sujeitos de pesquisa em sua integridade concomitantemente aliada a contribuição do progresso técnico e cientifico. Assim, compete a ele avaliar e acompanhar todos os aspectos éticos, em conformidade ao que ficou estabelecido na Declaração de Helsinque e demais declarações internacionais de direitos humanos.

Neste contexto, as instituições que realizam estudos clínicos envolvendo seres humanos devem privilegiar a criação do CEP como forma de valorizar e enriquecer a investigação, certificando que respeita os princípios éticos e contribui para o processo educativo dos pesquisadores, da instituição e dos membros integrantes da comissão. No que se refere à função consultiva, proporcionar a formação continuada em prol de melhores resultados e, para tanto, investir e incentivar a realização de seminários, palestras e cursos sobre os protocolos terapêuticos. 


\section{Abrangência}

Desde o momento da criação do CEP, deve ser elaborado o regimento interno que irá determinar sua competência, principalmente, se houver mais de um. No entanto, situação excepcional poderá ocorrer quando receber, a pedido do CONEP/CNS, para deliberar a respeito de pesquisa de outra instituição que ainda não tenha estabelecido a sua própria comissão, ou no caso do pesquisador ser proveniente de outra entidade. Neste último, todos os CEPs deverão emitir pareceres independentes que poderão coincidir ou não, segundo a VII 2.2 da Resolução n. 466/2012 CNS. Para haver a indicação devem ser considerados aspectos como: o acesso dos sujeitos ao CEP indicado, a possibilidade de acompanhamento do projeto, o perfil da instituição, a capacidade do CEP de receber a demanda adicional, a conformidade do CEP com as normas e a inscrição dos pesquisadores aos respectivos conselhos profissionais, procurando indicar um CEP do mesmo município (VII.2 da Resolução n. ำ 196/1996 do CNS).

Ainda sobre a abrangência e atuação dos CEPs, a resolução de 1996 prevê a necessidade de haver um funcionário administrativo responsável pelo atendimento aos pesquisadores e outros agentes, além de atuar zelando pela burocracia do órgão, no que se refere aos cronogramas de reuniões, horário de funcionamento e datas de emissão de pareceres, favorecendo a organização e comunicação entre os interessados pela extrema lisura e confiabilidade.

\section{Implantação}

Compete à direção da instituição as atribuições da gerência e da administração do Comitê de Ética em Pesquisa que, de acordo com o estabelecido na Resolução 240/1997 do CNS, deverá receber autorização do CONEP para iniciar os estudos investigativos e ter legitimada a liberação para a realização de pesquisas.

\section{A Escolha dos Membros do CEP}

O Comitê de Ética em Pesquisa deve ter em sua composição pessoas provenientes de áreas de conhecimentos diferentes a fim de efetivar o aspecto multidisciplinar e 
multiprofissional dos envolvidos. Estima-se, enquanto modelo ideal, que seja composto por juristas, teólogos, sociólogos, filósofos, pessoas que se dediquem ao estudo da bioética e pelo menos um representante dos usuários e, em proporção equilibrada entre homens e mulheres, de acordo com a Resolução n.196/1996 do CNS.

De acordo com o regimento interno de cada CEP podem haver critérios diferenciados para a escolha dos membros, desde que estes não sejam ofensivos aos estabelecidos por outros comitês e que seja sempre realizado de forma transparente, inclusive para convidar pessoas de fora da instituição, com a possibilidade de convites para consultores 'ad hoc' sempre que necessário. Os membros do Comitê de Ética em Pesquisa possuem mandato com duração de 3 anos e direito de renovação do registro que deve ser solicitado a cada mandato. Sempre que houver alteração de algum integrante, o CONEP deve ser cientificado, pois compete a ele a gerência institucional de todos os CEPs. O número de integrantes não pode ser inferior a sete membros.

Para fazer parte enquanto membro do comitê é imperioso que os consultores declarem suas possíveis ligações institucionais com a indústria farmacêutica, seja como pesquisador, consultor, palestrante, acionista ou outras formas de envolvimento que possam indicar conflitos de interesses, a fim de sempre manter a mais estrita autonomia nas deliberações necessárias.

\section{Representante dos Usuários}

A presença do representante dos usuários como membro do Comitê de Ética em Pesquisa é essencial para que a manifestação dos sujeitos ativos que se beneficiam dos serviços da instituição possa ser considerada. Talvez, a escolha desse indivíduo possa ser um pouco mais conturbada que os demais e, para tanto, a Resolução n. - 240/1997 do CNS sugere que a indicação seja realizada diretamente pelo Conselho Municipal de Saúde ou associações já estabelecidas com a instituição, pois, o fato de ser funcionário ou possuir qualquer vínculo de dependência com aquela, poderia comprometer a sua opinião. Ressalta-se que também para estes, é imprescindível o respeito ao direito dos cidadãos e usuários dos serviços, esperando-se que mediante a participação, todos sejam capazes de contribuir efetivamente nas discussões de forma profícua, considerando os interesses e preocupações da comunidade local. 


\section{Promoção da Formação Continuada dos Membros do CEP}

O direito à informação deve ser exercitado e para tanto se preconiza que seja facilitada a comunicação entre o Comitê de Ética em Pesquisa, seus membros e a comunidade em geral. Para tanto, deve ser realizado pelo menos um seminário anual, no qual sejam discutidos os aspectos éticos das pesquisas, bem como incentivada a utilização de meios eletrônicos para promover a troca de experiências entre os diferentes sujeitos envolvidos, valorizando, incentivando e financiando a formação continuada dos atuais e futuros integrantes. O capítulo III da recente Resolução n. $510 / 2016$ esclarece e normatiza a realização das pesquisas clínicas, sob o enfoque individual do investigado.

\section{Manutenção e Financiamento do CEP}

A organização e o funcionamento do Comitê de Ética em Pesquisa são responsabilidades da instituição, enquanto parte fundamental da infraestrutura necessária para a realização das pesquisas (laboratórios, funcionários, arquivos, material, etc). $O$ ideal é a mantenedora gerenciar o orçamento de todas as pesquisas realizadas no seu âmbito, pois, em hipótese alguma poderá haver cobrança para apreciação e emissão do parecer. O item III da Resolução n. - 196/1996 afirma que um importante objetivo secundário da pesquisa colaborativa é auxiliar no desenvolvimento da capacidade do país hospedeiro e das instituições auxiliares, para executar de maneira independente os projetos de pesquisas similares, incluindo a avaliação ética.

Como a participação dos membros é voluntária, ressalta-se a possibilidade da instituição prever incentivos para seus membros, estabelecendo carga horária específica a ser cumprida, pontuação para avaliação de produtividade acadêmica ou progressão funcional, entre outros, enquanto formas para retribuir com o empenho do colaborador perante as atividades propostas.

\section{Comitês de Ética em Pesquisa e a Linguagem Técnico-Cientifica}


A criação dos Comitês de Ética em Pesquisa enaltece a preocupação com o respeito à dignidade da pessoa humana, cuja atuação se caracteriza pela ação de controle social diante da hipercomplexidade existente nas pesquisas médico-científicos, disciplinadas pela condição de risco. Trata-se de colegiados interdisciplinares responsáveis pela pesquisa nacional, influenciando no progresso cientifico e tecnológico ao exercer atividades consultivas e educativas, avaliando de maneira detalhada e minuciosa os fatos e suas consequências, atuando no processo para obtenção de consentimento. Assim, é uma instância normativa, de recurso e de coordenação.

Aos CEPs cabe a aprovação de projetos das áreas de genética humana, reprodução humana, pesquisas em povos indígenas, pesquisa com cooperação estrangeira, pesquisas que envolvem biossegurança, pesquisas com novos equipamentos e pesquisas com procedimentos cuja aceitação ainda não está consagrada na literatura, mas que se justifica por sua 'vantagem social', ou seja, não excedam os benefícios potenciais e se com o ônus e bônus repartidos de forma equânime (6).

Conforme as determinações legais, os comitês conectam 0 desenvolvimento científico com o respeito à condição humana e à singularidade de cada individuo, contribuindo para a humanização do progresso científico uma vez que este exige estudos para responder ao inconformismo e desvendar os mistérios que envolvem a vida e suas interrogações infindáveis. São eles que movimentam a ciência, pois, a falta de preocupação com o rigor científico nas pesquisas relacionadas à saúde pode ser considerada como omissão diante da ausência de recursos essenciais, medicamentos ou estudos comprobatórios das moléstias existentes, literalmente 'coisificando' o homem.

O limite entre o possível e o abusivo é extremamente tênue, demandando uma análise minuciosa da pesquisa médico-científica envolvendo seres humanos, mediante o risco de serem reduzidos à condição de cobaia caso haja o desrespeito de direitos básicos de todos. Os Comitês de Ética em Pesquisa (CEPs) agem com munus publico para avalizar estudos clínicos e legitimá-los, constando que a pesquisa não acarreta prejuízo ou dano para os envolvidos, senão o respeito às pessoas, as considerando-as conforme suas necessidades e direitos, delimitando as práticas da ciência não só das áreas da saúde, mas também nas ciências humanas, como educação, sociologia, direito, antropologia, etc.

$\mathrm{Na}$ atualidade, trata-se de formações multicêntricas, envolvendo a cooperação ampliada e multinacional ensejando um exame mais atento quanto ao recrutamento de 
patrocinadores, pesquisadores e pacientes. O CONEP recebeu cerca de 1300 protocolos de áreas temáticas especiais, $80 \%$ dos quais envolviam projetos de novas drogas, multicêntricos e internacionais (6). O sistema CONEP/CEP é o gestor do controle social e ético e responsável pela determinação das práticas sanitárias brasileiras, adstrito aos órgãos do Ministério da Saúde, exigindo uma reflexão e juízo crítico para a tomada de decisão.

Em 1995, a Secretaria Nacional de Vigilância Sanitária deu licença para a importação de novas drogas referentes a 35 protocolos de pesquisa; e em 2000 para 747 protocolos, o que evidencia um aumento de mais de 20 vezes. Dados do FDA, organismo de vigilância sanitária americano, mostram que o número de pesquisadores fora dos EUA envolvidos nos projetos multicêntricos cresceu 7 vezes mais no período de 1990 a 1999 com maior participação da Europa do Leste e América Latina ${ }^{6}$.

A independência de atuação dos sistemas é constatada nas resoluções que concedem liberdade de trabalho aos seus membros determinando que eles "não podem sofrer qualquer tipo de pressão por parte de superiores hierárquicos ou pelos interessados em determinada pesquisa, devendo isentar-se de envolvimento financeiro ou conflitos de interesse" (item VII-12), contando com a participação de representantes de diferentes categorias na análise do projeto, visa agir com responsabilidade solidária, inclusive do Estado, por tratar de questões de saúde pública.

O crescimento de pesquisas clínicas envolvendo seres humanos exige atenção redobrada dos Comitês no Brasil que devem preocupar-se em estabelecer certa uniformidade de julgamentos, sob a pena de estudos equivalentes serem permitidos em determinada instituição e serem recusados em outras, contribuindo por acirrar ainda mais o dilema acerca da liberação destes estudos. O reconhecimento dos conflitos de interesses dentro do campo de atuação médico-científico parece já acontecer, porém, novas questões polêmicas surgem diariamente na prática, exigindo embasamento, reflexão e experiência de todas as áreas do conhecimento envolvidas. Um Sistema Integrado de Informações (SISNEP) - de todos CEPs e o CONEP, está em fase de implementação disponibilizando acesso a todos os interessados, objetivando consolidar a fiscalização necessária pelo órgão executivo federal.

Apesar de ainda haver muito a ser feito neste ínterim, há grandes avanços em curso, uma vez que o sistema ainda está aprendendo a identificar e resolver as demandas 
existentes para a efetivação do respeito aos direitos dos sujeitos de pesquisa, em cenário nacional, a partir das experiências e regulamentações mundiais iniciadas a partir da Declaração de Helsinque. Não são normas auto-aplicáveis e com experiência prévia. Ao revés, são sempre situações inéditas que, na maioria das vezes, não contam com referencial teórico e exemplificações práticas anteriores, o que dificulta a adoção de parâmetros éticos.

O processo de estruturação aconteceu a partir das diretrizes de atuação do próprio Sistema Único de Saúde (SUS), ao se preocupar com conselhos paritários, a partir da concepção do Conselho Nacional de Saúde disciplinada na Resolução n.ำ 196/96. Anterior a isso, havia a obrigação disciplinada pelo Conselho Federal de Medicina, que firmou o compromisso para a criação das Comissões de Ética Médica em todos os estabelecimentos de saúde, em conformidade com a Resolução n.․ 1215/1985, provocando divergência quanto à possível atuação das delegações, resolvidas posteriormente com a edição da Resolução $n .{ }^{\circ}$ 1/1988. Os conflitos éticos nas pesquisas médico-científicas são uma constante e devem estar claros desde o planejamento do estudo, pois, caso contrário, a investigação não será legitimada diante da ofensa a dignidade dos sujeitos de pesquisa, e assim, não irá contribuir para o avanço do conhecimento. Ou seja, não apresentará benefício capaz de justificar o 'sacrifício' suportado pelos pacientes ${ }^{2}$.

De acordo com estudo realizado sobre a existência e funcionamento de Comitês de Ética em Pesquisa ${ }^{3}$, dentre os vinte e seis (26) hospitais brasileiros pesquisados, 15, ou seja, 57,7\% possuem Comitês de Ética em Pesquisa. Nos 11 demais, ou seja, 52,3\% não têm, e assim avaliam os projetos por meio das Comissões de Ética Médica ou Comissão Científica ${ }^{4}$. Diante dos dados, os pesquisadores do referido estudo afirmam:

2 - No século XVIII destacam-se as pesquisas realizadas por Edward Jenner (1749-1823) que testou vacinas de varíola no seu próprio filho e nas crianças do bairro e a de Johann Jorg (1779-1856) que engolia drogas para comprovar suas propriedades - Vide https://pt.wikipedia.org/wiki/Edward Jenner e https://de.wikipedia.org/wiki/Johann Christian J\%C3\%B6rg respectivamente.

3 - Envolveu 26 hospitais e 37 pesquisadores, sob a responsabilidade de Carlos Fernando Frascisconi, Délio José Kipper, Gabriel Oselka, Joaquim Clote e José Roberto Goldin publicado na Revista de Bioética v. 3, n.1 intitulado Comitês de Ética em Pesquisa Levantamento de 26 hospitais brasileiros, disponível em $<$ revistabioetica.cfm.org.br/index.php/revista_bioetica/article/view/431/499>. Acesso em 11 de out. 2015.

4 - Recomenda-se a leitura do estudo, pela riqueza de dados apresentados para o cenário brasileiro, informando os critérios de escolha dos membros e suas particularidades, bem como a realização de reuniões e índices de aprovação e rejeição dos projetos, a partir dos fatores que mais o influenciam. 
Os resultados destes estudos demonstraram em primeiro lugar que é lamentável a forma como vem sendo realizada a pesquisa biomédica no Brasil, em relação aos parâmetros estabelecidos em normas nacionais e internacionais. Em segundo lugar, a necessidade de uma ampla divulgação das normas nacionais e internacionais de pesquisa em saúde, do papel dos Comitês de Ética em Pesquisa e a sua diferença em relação às Comissões de Ética Médica.

Dessa feita, verifica-se que o sistema CEP/CONEP já possui relevante história no território nacional e influencia de forma considerável para o estabelecimento das políticas de saúde pública, constituindo o direito sanitário brasileiro, com aspectos como o respeito aos direitos dos pacientes, apesar de ainda haver muito a ser construído. A nova Resolução n. 466/2012 é considerada um avanço, porém, ainda não concluiu o tema que constantemente precisa ser revisto pelo próprio progresso científico, exigindo acima de tudo uma ética comunicativa consensual capaz de justificar as tomadas de posições.

\section{A Importância da Atuação dos Comitês de Ética em Pesquisa para a Normatização}

A literatura evidencia que os Comitês de Ética em Pesquisa apresentam ausência de uniformidade de critérios para a deliberação, seja para permitir o estudo ou ao contrário, em função de razões como distorções ideológicas, culturais ou pessoais dos membros dos Comitês. Diante deste fato, não há descoberta capaz de resolver os conflitos morais, que na grande maioria das vezes, é superado através da realização de convenções. Fato agravado pela dificuldade quanto à escolha dos membros que irão integrar o Comitê de ética Médica, pois, suas convicções pessoais podem intervir de maneira direta em suas decisões. Assim, a própria profissão do indivíduo pode ser um fator determinante considerável em sua tomada de posição.

Para Habermas (7), todo tipo de institucionalização possível de um discurso prático supõe suas próprias representações sociais sendo determinado pela interpretação e crítica das culturas envolvidas. Assim, a "ciência passou a ocupar, ao menos na maioria das sociedades ocidentais, as funções de depositária de esperanças e de guia de conduta" (8). A história da humanidade aponta que as guerras mundiais podem ser compreendidas como verdadeiros laboratórios onde foram utilizados gases tóxicos, veículos motorizados e a aviação enquanto avanços tecnológicos, além de todos os testes realizados em prisioneiros que eram conduzidos de forma desrespeitosa e humilhante para serem 
mutilados ou assassinados de forma cruel. A temível 'arma biológica', cada vez mais complexa e poderosa, também é proveniente dos avanços da ciência. Os exemplos demonstram que as descobertas tecnológicas podem ser utilizadas para concretizar ações de destruição em massa colocando em dúvida as reais intenções dos cientistas.

As pesquisas médico-científicas têm no homem o principal sujeito da discussão ética, no entanto, percebe-se a necessidade de uma visão integral da temática incluindo o meio ambiente como um todo, inclusive com todas as demais formas de vida e a relevância que merecem. A adoção de apenas um sentido comprometeria todo o porvir e o respeito pela diversidade. Por outro lado, é imperioso delimitar os limites de atuação através das leis e normas enquanto instrumentos de controle social capaz de estabelecer a fronteira entre 0 possível e o impossível, o permitido e o proibido, determinando o que se entende como correto para aquela situação. Esse é o papel primordial dos Comitês de Ética em Pesquisa dentro do sistema CEP/CONEP, que devem escolher livremente a tomada de posição de forma a conduzir o futuro da humanidade, conforme a dinâmica da vida 5 .

No que se refere à questão burocrática, confirma-se que os Comitês de Ética em Pesquisa são organizações, independentemente de sua atuação ser mais flexível ou não, que seguem critérios racionais e hierárquicos institucionalizados, estabelecendo relações de interdependência com o seu entorno, através de pesquisadores, pacientes e futuros beneficiários dos estudos realizados. De forma preliminar, não pertencem ao sistema jurídico, pois, preocupam-se em normatizar situações de pesquisas envolvendo seres humanos, protegendo e defendendo, no sentido de justificar o sacrifício suportado por eles, em benefício de progresso científico futuro. No entanto, ocorre que em determinados casos os pesquisadores não concordam com o parecer emitido pelos Comitês, que são majoritariamente compostos por profissionais provenientes da área da saúde, que não dominam as regras referentes aos direitos fundamentais preconizados na Carta Magna.

Desta feita, compreende-se que por falta de informações, os cidadãos não atentaram ainda para a possibilidade de judicializar os dilemas que dificulta a realização

\footnotetext{
5 Tomanik (8) relata casos emblemáticos, quando pesquisadores desejavam continuar estudo clínico significativo com material genético depositado em instituição, por haver sido exigido o consentimento livre e esclarecido dos doadores, já que não havia identificação e grande parte estava com prazo de validade expirado, os tornando inviável para outros fins, ou ainda a situação seria aproveitar informações já disponíveis em trabalho social realizado, sem nenhuma vinculação a projeto de pesquisa. Foi obtida as devidas autorizações, porém o Comitê de Ética em Pesquisa não permitiu a continuação, justamente, por essa fase, não estar dentro do projeto apresentado para sua análise.
} 


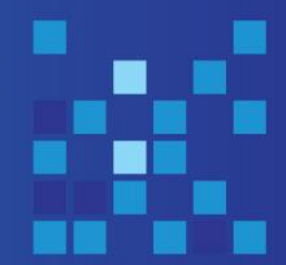

das pesquisas médico-científicas, seja no sentido de permitir ou proibir estudos abusivos à dignidade humana. Situação pitoresca foi a que aconteceu com a pesquisa intitulada 'Hetorogeneidade de vetores de malária no Amapá', iniciada em 2003, objetivando analisar os vários tipos de transmissores da malária na região, especificamente na cidade de Santana, na comunidade de Pirativa ${ }^{6}$.

Os moradores da referida comunidade denunciaram à promotoria local que a realização desta pesquisa sobre a malária pagava aos indivíduos para servirem de cobaias humanas, ou seja, os 'voluntários' aceitaram receber $R \$ 108,00$ (cento e oito reais) para capturarem e alimentarem mosquitos transmissores da malária, disponibilizando seus braços e pernas como armadilha durante o período da noite. A respeito deste caso, Santos (9) relata que sujeitos que "mal sabiam escrever o nome" assinaram o contrato com essas clausulas ${ }^{7}$. Diante de um relevante impasse ético, em dezembro de 2005, o CNS decidiu suspender o estudo até que a investigação fosse concluída, encaminhando o caso para o Ministério Público (9).

Em 11 de dezembro de 2013, o Tribunal Regional Federal da 1ㄹ Região - TRF1 definiu o valor de $R \$ 50.000,00$ (cinquenta mil reais) corrigidos a cada um dos participantes que serviram de 'cobaias humanas' para essa pesquisa, a título de indenização material e moral, entendendo o caso como "aproveitamento da hipossuficiência financeira e cultural daquelas pessoas humildes" ${ }^{\text {. }}$. O citado exemplo não despreza a importância e necessidade de estudos clínicos envolvendo doenças como a malária que requer a captura de mosquitos transmissores, porém, ressalta que estas não devem desconsiderar o ser humano e sua condição de saúde, principalmente ao se tratar de pessoas pertencentes a comunidades socialmente vulneráveis.

A preocupação com o direito à vida e à dignidade da pessoa humana é norma constitucional proveniente dos direitos humanos, reforçando a necessidade de atenção quanto às pesquisas realizadas com eles, devendo os pesquisadores considerar as

\footnotetext{
${ }^{6}$ Segundo Santos (9) a pesquisa foi coordenada pela Universidade de Flórida e financiada pelo Instituto Nacional de Saúde dos EUA (NHI), com a parceria da Fundação Oswaldo Cruz (FIOCRUZ), da Universidade de São Paulo (USP), da Fundação Nacional de Saúde (FUNASA) e da Secretária Estadual de Saúde do Amapá (SESA), com o objetivo de analisar os vários tipos de transmissores da malária na região.

$7 \mathrm{Em}$ nota oficial a FIOCRUZ explicou que apesar do projeto de pesquisa ter sido aprovado pelo CEP da FIOCRUZ e pelo CONEP do CNS, quando o foi, em 2001, não mencionava o pagamento dos colaboradores nem sua utilização como "isca humana". Posteriormente descobriu-se que esse fato fora omitido na versão em português do Projeto (9).

8 Disponível em www.prap.mpf.mp.br/noticia.php?cdnoticia=3714. Acesso em 12 de out. de 2015.
} 
diferenças culturais a partir da informação clara, relevante, precisa e compreensível, de forma a ser devidamente avaliada pelo participante do estudo. Destaca-se ainda a dúvida quanto a realização de outras pesquisas com os mesmos parâmetros, já que pela hipossuficiência do paciente, ele muitas vezes não consegue reivindicar seu direito.

A nova Resolução do Conselho Nacional de Saúde de n. 466 de 2012 definiu por sua vez os direitos dos voluntários que participam das pesquisas e abre a possibilidade de recompensa financeira a eles, até então proibido no Brasil, além de estabelecer o prazo máximo de 60 dias para a emissão do parecer dos Comitês de Ética em Pesquisa, concedendo prioridade a estudos considerados estratégicos para o Sistema Único de Saúde (SUS), além disso a Resolução n. 510 de 2016, detalhou os requisitos para o consentimento dos sujeitos investigados. Mesmo que a recompensa financeira trate apenas do reembolso de gastos pessoas como deslocamento e alimentação dos voluntários, a intenção é incentivar a motivação para colaborar com a realização de estudos clínicos, conclamando todos a uma verdadeira reflexão ética sobre o tema, mediante a perspectiva de estarmos todos diante de uma nova profissão, 'ser cobaia humana ou guinea pig'9, como já acontece em outros países. Evidencia-se, portanto, o realce para a importância da comunicação estabelecida pelos Comitês de Ética em Pesquisa no futuro da realidade brasileira, para a condução das pesquisas envolvendo seres humanos e sua responsabilidade com o porvir, diante do questionamento sobre os limites para a pesquisa científica. Machado (4), aduz:

A compreensão das decisões como comunicação organizacional pressupõe adensar o conhecimento sobre a forma como as organizações se autoobservam e autodescrevem, bem como sobre as premissas decisórias, como a distribuição dos papéis e tarefas (organograma), recrutamento dos membros e interações organizacionais. Aprofundar o conhecimento da cultura organizacional significa desvendar parte das premissas decisórias.

São os pareceres técnicos emitidos pelos comitês que operacionalizam o controle social daquilo que é ou não permitido, enquanto estudo que será viável para a qualidade de vida dos indivíduos como um todo, em termos de avanços biomédicos, comprovando as interações realizadas pela comunicação do permitido ou não. São as decisões por eles

\footnotetext{
${ }^{9}$ Recomenda-se a leitura da livro The professional Guinea Pig (sem edição em português) de Roberto Abadie.
} 
estabelecidas que determinam quais práticas médicas serão que futuramente adotadas, e consequentemente influenciarão na qualidade de vida dos cidadãos brasileiros.

\section{Considerações Finais}

As inquietações do homem quanto ao desconhecido impulsionam a busca por resposta que motivam estudos e pesquisas em prol da comprovação científica para os mais diversos questionamentos. Assim, a cada avanço percebe-se que há muito a ser feito e assim, está em constante conflito ético para determinar qual o limite de atuação das áreas de conhecimento, como acontece com a biomedicina ao pretender aperfeiçoar ações que amenizem as mazelas humanas.

Neste contexto, o sistema CEP/CONEP se destaca quanto à regulamentação das pesquisas envolvendo seres humanos, pois possui propriedades (institucionais, organizacionais, hierárquicas e normativas) para administrar e gerir o 'valor' do ser humano nas sociedades atuais. Ademais, a realidade é alterada a cada segundo com a comprovação de novas descobertas em avanços que parecem estar uma busca sem fim. A partir desse raciocínio, constata-se a sutileza e hipercomplexidade dos dilemas éticos dentro de uma visão sistêmica, cuja conclusão parece algo distante de se alcançar.

Os avanços científicos ao longo da história da humanidade nos mostra que a cada novo pensar surgem outras interrogações que continuam a impulsionar o interesse e a necessidade das pesquisas. Como por exemplo, no âmbito médico-científico faz-se preciso compreender se há diferenças entre o agir (comportamento) e a observação de riscos entre os pacientes voluntários e àqueles que já colaboram quase de forma profissional, mantendo-se economicamente através dos benefícios como lanches e outros itens essenciais.

Assim, questiona-se o possível surgimento de um novo nicho do mercado financeiro a ser explorado, mediante a ocupação remunerada de pessoas excluídas do contexto social por diferenças financeiras e econômicas, em estudos médico-científicos. Em caso positivo, argumenta-se a imparcialidade dos envolvidos quanto à avaliação do aspecto risco versus benefício diante da participação humana em pesquisas clínicas.

A resolução brasileira de 12 de julho de 2012, n. 0 466, implicitamente inaugura esse novo conflito ético, pois, se ainda não pacificamos a utilidade do estudo com seres 
humanos, agora estamos diante de mais um complicador: a possibilidade de o 'voluntariado' ser exercido com habitualidade, como acontece com os guinea pig estadunidenses, por exemplo, pois a posterior Resolução, datada de 7 de abril de 2016, abordou com excelência a importância do assentimento/consentimento dos sujeitos de pesquisa, preconizando, uma preocupação com a temática, pois a cada dia, cresce sua importância e utilização. A única certeza é que a celeuma acerca desta problemática continua e parece persistir apesar de alterar o enfoque de estudo.

Os Comitês de Ética em Pesquisa no Brasil são os principais responsáveis por determinar quais políticas públicas sanitárias serão adotadas internamente, para normatizar os protocolos médicos e demais pesquisas envolvendo os seres humanos. É a partir das delimitações dos comitês que são determinadas as deliberações futuras. Delas decorrem outras particularidades, como a possibilidade de serem publicadas, divulgando os estudos concluídos, tanto no sentido de serem aprimorados como desconsiderados por não demonstrarem prognósticos satisfatórios. Serão eles, o responsável pela proteção à dignidade dos seres humanos e, portanto, obediência ao mais básico dos direitos, a vida.

Conforme levantamento bibliográfico houve avanços significativos no sistema CEP/CONEP a partir das suas deliberações, porém, talvez, chegue o momento de haver a necessidade de ser normatizada por uma legislação, atendendo aos princípios bioéticos universais, no que refere à situação específica da profissão de cobaia humana, para minimizar os conflitos de interesses.

Diante da magnitude de sua atuação, os Comitês de Ética em Pesquisa podem ser responsabilizados solidariamente, pela condição humana diretamente envolvida nas pesquisas médico-científicas, haja vista que determinados estudos não são autorizados por não haver respaldo legal quanto ao respeito da singularidade humana e na mais estrita concepção de direito geracional. Assim, a pesquisa envolvendo seres humanos é por si só autorreferente no porvir de políticas publicas, determinando o grau de satisfação dos tutelados em termos de avanços biomédicos, como por exemplo, a própria indústria farmacêutica.

Os discursos estabelecidos dentro dos Comitês de Ética em Pesquisa, enquanto organização multidisciplinar revelam mitos e verdades sobre o que será adotado como benéfico para o sistema saúde pública, estabelecendo a conexão entre a expertise das 
áreas de conhecimento envolvidas e a sua judicialização, que sempre irão exigir novos estudos empíricos, diante da velocidade do progresso científico e tecnológico.

\section{Referências}

1. Bobbio, M. O doente imaginado: os riscos de uma medicina sem limites. Tradução Mônica Gonçalves. São Paulo: Ba2.mboo, 2014.

2. Luhmann, N. Organización y decisión: Autopoiesis, acción y entendimiento comunicativo. Trad. Dario Rodríguez Mansilla. Barcelona: Antropos, 1997.

3. Popper, K. R. A lógica da pesquisa científica. São Paulo: Editora Cultrix, 2013.

4. Machado, B. A. Justiça criminal: diferenciação funcional, interações organizacionais e decisões. 1 ed. São Paulo: Marcial Pons, 2014.

5. Bourdieu, P. O Poder Simbólico. 5 ed. Rio de Janeiro: Bertrand Brasil, 2002.

6. Palácios, M. Ética na pesquisa - I. Ética em pesquisa em seres humanos. In Palácios, M.; Martins, A.; Pegoraro, O. A (org.) 2001. Ética, ciência e saúde: desafios da bioética. Petrópolis: Vozes, 2001.

7. Habermas, J. Teoria do Agir Comunicativo. Revista de Humanidade, Macapá, n.6, p.0117, Dez., 2012. 8

8. Tomanik, E. A. A ética e os comitês de ética em pesquisa com seres humanos. Psicologia em Estudo, Maringá, v.13, n.2, p.395-404. abri./jun. 2008.

9. Santos, R. C. S.; Santos, E. C. S. Malária: cobaias humanas do Amapá. Estação Científica, Macapá, v.1, n.2, p.143-150, 2011.

Recebido em: 18/9/2016

Aprovado em: 29/9/2016

\section{Como citar este artigo:}

Thomasi, TZ. Comitês de Ética em Pesquisa: da linguagem técnico-cientifica à normatização. Revista Cadernos Ibero-Americanos de Direito Sanitário. 2016 jul./set, 5(3):10-30. 